To the Editor:

Dept. of Traumatic and Orthopaedic Surgery,

Dear Madam,

\section{PNEUMOTHORAX DUE TO SOCCER INJURY}

Soccer is the most popular sport in Saudi Arabia and a recent study indicated that more than $60 \%$ of all sports injuries here were due to soccer. We wish to report a case of a pneumothorax due to injury in a soccer game.

A 19 year old male was seen in the emergency room with complaints of pain in the left side of his chest and breathlessness on exertion. He gave a history of colliding with another player during a soccer game six days previously. The pain was stabbing in nature localised to the left side of the chest and due to the pain he did not complete the game. He was seen in a private clinic and given analgesics. During the succeeding days the pain persisted and radiated to the left shoulder. On examination pulse was 88 per minute, respiratory rate 28 per minute, there was decreased expansion of the chest on the left side and auscultation revealed diminished air entry on the left.

The chest radiograph showed bilateral pneumothorax ( $25 \%$ on the left side and $10 \%$ on the right). A bronchogram did not reveal any abnormality. The patient was successfully treated with an intrathoracic chest tube on the left side. A week later radiographs of the chest showed full expansion of both lungs. Six weeks later the patient returned to soccer.

\section{COMMENTS}

Pneumothorax due to trauma is well known. A sportsman may have minimal signs and symptoms. Meticulous clinical examination and a chest radiograph must be done to rule out pneumothorax in suspected cases. We believe that an early diagnosis is necessary to prevent complications of persistant pneumothorax which may debilitate young sportsmen.

$$
\begin{aligned}
& \text { Yours faithfully, } \\
& \text { Dr. Mir SADAT-ALI, } \\
& \text { Registrar in Orthopaedics } \\
& \text { Dr. A. L. AL-ARFAJ, } \\
& \text { Consultant General Surgeon } \\
& \text { Dr. Mohammed MOHANNA, } \\
& \text { Consultant General Surgeon }
\end{aligned}
$$

To the Editor:

Cardiff Royal Infirmary

\section{Dear Madam,}

\section{BREAK DANCING, THE NEED FOR SUPERVISION}

Another leisure activity has crossed the North Atlantic and, following skate boards, BMX bikes and jogging, we now have break dancing.

In recent months we have seen several youngsters with minor break dancing injuries and we would like to bring to the attention of readers to two unusual injuries which illustrate the need for supervision of break dancing.

A fourteen year old boy presented with an eight week history of left hip and groin pain. His interest in break dancing had previously resulted in several episodes of minor back trauma. Six months prior to referral he suffered a severe left hamstring strain when a provisional diagnosis of malignancy had been suggested to the family as a pelvic $X$-ray taken before referral showed bony overgrowth and periosteal reaction of the left ischium.

Our investigations showed him to be suffering from ischial apophysitis related to continuing regular dancing following his hamstring injury. He responded well to treatment with rest, physiotherapy and non-steroidal antiinflammatory agents.

Another fourteen year old boy dancing on a concrete floor jumped forward onto his hands, mistimed the move and struck his head on the floor. He was not knocked out but felt unwell and subsequently noticed facial asymmetry. Examination showed an isolated lower motor neurone right facial nerve palsy. He was treated conservatively with a short period of in-patient observation. On review in clinic his facial palsy had resolved.

Break dancing carries many of the risks of conventional dancing and gymnastics but, unlike them, is usually carried out without supervision. Whilst the activity has much to offer the child and teenager it lacks suitable venues and training. Youth clubs, dance schools and community groups could supply these facilities.

$$
\begin{aligned}
& \text { Yours faithfully, } \\
& \text { S. R. JOHNSON, } \\
& \text { MBChB, FRCS, Registrar } \\
& \text { D. G. JONES, MBChB, FRCS, MRCP }
\end{aligned}
$$

